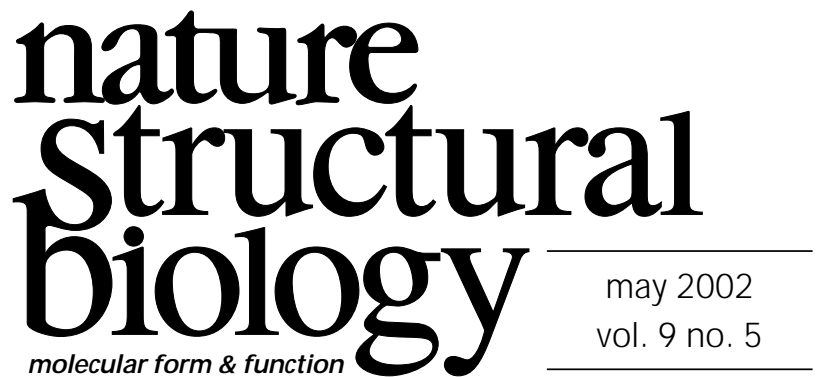

\title{
Remembering the vanguard
}

With the recent passing of some prominent members of the structural biology community - Paul Sigler, G.N. Ramachandran, Don Wiley and Max Perutz - our thoughts turn to their extraordinary contributions to the field and their legacy of results and progenies. Undoubtedly, over the course of their careers each of these scientists, like many others, accumulated an abundance of personal documents related to their work - tucked away in notebooks and file cabinets. Perutz more formally collected some of his thoughts in books and essays on the history of science, some of which may be found on the Nobel Foundation web site (http://www.nobel.se). Both these historical essays and personal document collections are valuable as first-hand accounts of how science was done and how major discoveries were made. Several groups have realized this and have begun to digitize such material for posting on the web. While some may consider this trend intrusive, others have embraced it and hope that more collections will be made available to the public.

In this spirit, two web sites now offer insight into the life and work of Linus Pauling who, along with Perutz, was a founding member of the field of structural biology. Impressively, 46 of Pauling's research notebooks (covering the years 1922-1994) are now displayed online as PDF files in the special collections section of Oregon State University's library web site (http://osulibrary.orst.edu/specialcollections/). Pauling earned his undergraduate degree at Oregon State University, and all of Pauling's papers were donated to the university. The site presents material that takes the reader through Pauling's career and highlights some of the most interesting pieces in the collection.
A parallel exhibit about Pauling opened in February of this year on the Profiles in Science site sponsored by the National Library of Medicine (http://profiles.nlm.nih.gov/).

What makes the Pauling document collection particularly interesting is not only the chance to see the raw development of key scientific principles, but also the opportunity to sift through the personal bits of information that pepper his notes. Unlike many scientists, Pauling used his research notebooks as both scientific records and personal diaries. Although at times it can be difficult to decipher his handwriting, one can find passages relating to his thoughts on his diet, the building and maintenance of his home, the injury of his wife Ava Helen in a car accident, his cancer diagnosis, and the Gulf War - all interspersed among equations and experimental designs.

The web sites mentioned here - Oregon State University special collections, Profiles in Science, and the Nobel Foundation site - also provide information about other scientists and are certainly worth visiting. Each collection has essentially the same goal, well stated on the Oregon State University site: "to document the development of science and technology in the 20th century." The curators of these sites realize that while it is possible to chart the development of scientific knowledge through the published literature, it is impossible to recreate the thought processes of the scientists involved. This is where personal document collections come in, revealing that seldom is anything as straightforward as it appears in a polished research paper. That should be reassuring to all of the young scientists who will sadly not be fortunate enough to hear it from members of the vanguard in person. 